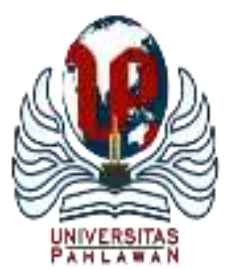

Edukatif : Jurnal Ilmu Pendidikan Volume 3 Nomor 6 Tahun 2021 Halm 4057 - 4065

EDUKATIF: JURNAL ILMU PENDIDIKAN

Research \& Learning in Education

https://edukatif.org/index.php/edukatif/index

\title{
Strategi Pemasaran Jasa Pendidikan dalam Meningkatkan Daya Saing Sekolah Menengah Atas di Era New Normal
}

\author{
Moh. Rofiki ${ }^{1 凶}$, Lukman Sholeh ${ }^{2}$, Abdur Rozak Akbar ${ }^{3}$ \\ Universitas Nurul Jadid, Paiton Probolinggo, Indonesia ${ }^{1,2,3}$ \\ E-mail : mohrofiki1984@gmail.com ${ }^{1}, \underline{\text { lukmansholeh211199@gmail.com }}^{2}, \underline{\text { rozaq04042000@gmail.com }}^{3}$
}

\begin{abstract}
Abstrak
Fokus tulisan ini adalah implementasi pemasaran jasa pendidikan di lembaga pendidikan yang sekarang berada dalam era kenormalan baru karena dampak pandemi covid-19. Penelitian ini merupakan penelitian kualitatif deskriptif dengan pendekatan studi kasus. Tujuan penelitian ini adalah dapat mendeskripsikan secara utuh serta menyeluruh tentang strategi pemasaran jasa pendidikan dalam meningkatkan daya saing sekolah di SMA Nurul Jadid Paiton Probolinggo. Teknik pengumpulan data yang digunakan dalam penelitian ini adalah observasi, interview, serta studi dokumentasi. Informan penelitian yaitu kepala sekolah, bagian humas, guru, serta siswa. Teknik analisis data menggunakan analisis data Miles dan Hubbeman terdiri dari mereduksi data, menyajikan data, seta penarikan kesimpulan. Hasil penelitian ini menyimpulkan bahwasanya strategi pemasaran jasa pendidikan dalam meningkatkan daya saing sekolah di SMA Nurul Jadid terdiri dari beberapa strategi yang digunakan yaitu strategi pemasaran jasa pendidikan secara langsung, tidak langsung serta deferensiasi.
\end{abstract}

Kata Kunci: Strategi Pemasaran Jasa, Bauran Pemasaran Pendidikan, Daya Saing, Era New Normal

\begin{abstract}
The focus of this paper is the implementation of marketing education services in educational institutions which are now in the new normal era due to the impact of the COVID-19 pandemic. This research is descriptive qualitative research with a case study approach. The purpose of this study is to be able to fully and thoroughly describe the marketing strategy of educational services in increasing school competitiveness at SMA Nurul Jadid Paiton Probolinggo. Data collection techniques used in this study were observation, interviews, and documentation studies. Research informants are the principal, the public relations department, teachers, and students. Data analysis techniques using Miles and Hubbeman data analysis consist of reducing data, presenting data, and drawing conclusions. The results of this study conclude that the marketing strategy of educational services in increasing the competitiveness of schools at SMA Nurul Jadid consists of several strategies used, namely direct, indirect, and differentiation marketing strategies for educational services.
\end{abstract}

Keywords: Service Marketing Strategy, Educational Marketing Mix, Competitiveness, New Normal Era

Copyright (c) 2021 Moh. Rofiki, Lukman Sholeh, Abdur Rozak Akbar

$\triangle$ Corresponding author:

Email : mohrofiki1984@gmail.com

DOI $\quad:$ https://doi.org/10.31004/edukatif.v3i6.1327

ISSN 2656-8063 (Media Cetak)

ISSN 2656-8071 (Media Online)

Edukatif : Jurnal Ilmu Pendidikan Vol 3 No 6 Tahun 2021 p-ISSN 2656-8063 e-ISSN 2656-8071 
4058 Strategi Pemasaran Jasa Pendidikan dalam Meningkatkan Daya Saing Sekolah Menengah Atas di Era New Normal - Moh. Rofiki, Lukman Sholeh, Abdur Rozak Akbar

DOI: https://doi.org/10.31004/edukatif.v3i6.1327

\section{PENDAHULUAN}

Semenjak diberlakukannya Undang-Undang Nomor 20 Tahun 2003 tentang sistem pendidikan nasional sebagai salah satu payung hukum akan pengelolaan pendidikan seacara nasional, perkembangan sekolah sebagai lembaga pendidikan mengalami perkembangan dan kemajuan yang sangat pesat. Hal ini terjadi sebagai bagian dinamika sistem dan regulasi dalam lembaga pendidikan tersebut. dimana pengelolaan tersebut meliputi pengelolaan metode, materi, pengembangan peserta didik, serta pengenalan lembaga pendidikan kepada konsumen pengguna jasa pendidikan yaitu masyarakat (Abrori, 2015).

Lebih lanjut, sekolah sebagai sebuah lembaga yang bertujuan untuk mencapai tujuan pendidikan nasional yang kegiatannya melalui proses pembelajaran harus menetapkan visi yang hendak dicapai oleh lembaga tersebut (Ananda \& Fadhilaturrahmi, n.d.). Salah satu strategi yang dapat digunakan oleh sekolah untuk mengenalkan visinya kepada pengguna jasa pendidikan yaitu strategi pemasaran (Margareta et al., 2018). Dimana penggunaan strategi yang tepat akan menetukan keberhasilan sekolah mewujudkan tujuan yang telah ditetapkan. Oleh sebab itu dalam melaksanakan kegiatan pemasaran tersebut setiap sekolah mempunyai yang berbeda-beda tergantung kepada kebutuhan dan keadaan sekolah tersebut. Terdapat sebagian sekolah yang dominan dalam melakukan pemasaran menggunakan bauran pemasaran, disisi lain terdapat pula sekolah dalam melakukan pemasaran memadukan antara pemasaran konvensional dengan digital (Ariwibowo, 2019).

Mengapa sekolah perlu melakukan pemasaran? Tentunya hal ini mutlak dilakukan oleh sekolah mengingat besarnya dampak yang dapat diperoleh sekolah tersebut. Menurut Wijaya dalam (Abrori, 2015) kegiatan pemasaran harus dilakukan oleh sekolah karena: 1) untuk menyakinkan masyarakat atau pelanggan pendidikan bahwasanya sekolah yang dikelola masih eksis; 2) untuk meyakinkan masyarakat atau pelanggan bahwasanya layanan jasa yang dilakukan sekolah relevan dengan kebutuhan mereka; 3) untuk memeperkenalkan jenis dan macam jasa pendidikan secara luas kepada masyarakat atau pelanggan jasa pendidikan; serta 4) agar eksistensi sekolah yang dikelola tidak ditinggalkan oleh masyarakat atau pelanggan, dimana pemasaran ini dilakukan oleh sekolah bukan hanya mengejar bisnis semata akan tetapi melainkan bentuk tanggung jawab sekolah kepada masyarakat atau pelanggan akan bentuk layanan jasa yang telah, sedang, dan akan dilakukan oleh sekolah tersebut.

Dalam era kenormalan ini dimana sekolah dihadapkan kepada banyaknya persoalan mulai dari pelaksanaan blended learning yang dilaksanakan melalui tatap muka dan melalui daring, percepatan digitalisasi dalam pelaksanaan pembelajaran oleh guru di sekolah, dll (Diana \& Rofiki, 2020). Hal ini tentunya juga menjadi persoalan bagi sekolah dalam melakukan pemasaran jasa pendidikannya kepada masyarakat atau pelanggan. Lembaga pendidikan dalam hal ini adalah sekolah sebagai penghasil jasa pendidikan, dahulu hanya dipandang penjual pasar semata, dimana calon pelanggan jasa pendidikan berlomba mendaftarkan dirinya ke sekolah tanpa banyak persaingan dengan sekolah lain. Akan tetapi kondisi sekarang tidak lagi seperti dulu dimana sekarang pertumbuhan sekolah sangat pesat mulai dari tingkat pendidikan usia dini sampai perguruan tinggi (Abrori, 2015). Ditambah lagi masyarakat sudah banyak yang paham dalam memilih sekolah yang sesuai dengan keingginnya sehingga sekolah dalam kondisi sekarang dituntut dapat mengambil hati para calon pelanggan. Selain itu tentunya juga akan terjadi persaingan yang sangat ketat antar sekolah dalam memperoleh jumlah siswa dan untuk membuktikan eksistensinya kepada masyarakat atau pelanggan. Sekolah dapat survive atau tidaknya ditentukan oleh kemampuan berkompetisi sekolah tersebut dimana sekolah yang tidak memiliki daya saing akhirnya akan ditinggalkan pelanggannya. Oleh sebab itu sekolah harus inovatif dan kreatif dalam mendesain pembelajaran sehingga output yang dihasilkan berkualitas (Siahaan et al., 2021).

Berdasarkan beberapa permasalahan di atas, maka penulis berminat untuk mengadakan penelitian "Strategi Pemasaran Jasa Pendidikan Untuk Meningkatkan Daya Saing Sekolah Menengah Atas Di Era New 
4059 Strategi Pemasaran Jasa Pendidikan dalam Meningkatkan Daya Saing Sekolah Menengah Atas di Era New Normal - Moh. Rofiki, Lukman Sholeh, Abdur Rozak Akbar

DOI: https://doi.org/10.31004/edukatif.v3i6.1327

Normal" dengan objek penelitian di SMA Nurul Jadid. Adapun tujuan penelitian adalah untuk mengetahui implementasi strategi pemasaran yang dilaksanakan dalam meningkatkan daya saing sekolah.

Terma strategi berasal dari bahasa Yunani yaitu "stratagos" yang berarti jenderal militer. Dengan kata lain strategi merupakan cara menempatkan pasukan dalam medan perang agar dapat mengalahkan musuh (Labaso, 2019). Lebih lanjut dalam KBBI Daring (Kemendikbud RI, 2016) definisi strategi merupakan sebuah rencana yang cermat mengenai kegiatan untuk mencapai sasaran dan tujuan tertentu. Dengan redaksi yang berbeda dan lebih rinci lagi menurut Laurence dan Gluecek strategi ialah suatu rencana terintegrasi yang menghubungkan keunggulan perusahaan dengan tantangan lingkungan yang dirancang untuk mencapai tujuan perusahaan dengan pelaksanaan yang tepat (Laurence \& Glucek, 1998). Sedangkan menurut Bittel sebagaimana dikutip Faizin, (2017), strategi merupakan suatu rencana yang mendasar dalam mencapai tujuan corperation. Dengan demikian berdasarkan berbagai penjelasan dapat diberikan pengertian bahwasanya strategi adalah suatu rencana strategis dan fundamental dari suatu organisasi untuk mencapai tujuan.

Jasa dalam pandangan Kotler merupakan tindakan atau kinerja individu yang ditawarkan kepada orang atau kelompok lain yang sifatnya tidak berwujud dan tidak menimbulkan kepemilikan (Khasanah, 2015). Lebih lanjut jasa menurut Machali dalam (Khasanah, 2015) memiliki karakteristik yang unik diantaranya adalah: a) intingible; b) inseparability; c) variability; d) perishability; e) konsumen bagian internal produksi jasa; f) tidak dapat disimpan pada saat dihasilkan; serta g) kualitas jasa tidak dapat diperbaiki pada saat produksi karena terjadi secara real time.

Pemasaran adalah suatu proses sosial serta manajerial yang terdiri dari kegiatan-kegiatan penting dimana seseorang atau individu memperoleh keinginan serta kebutuhan dengan melakukan pertukaran dengan orang lain (Labaso, 2019). Dimana menurut Machali dalam Khasanah (Khasanah, 2015) adalah proses pemasaran tersebut dipengaruhi oleh sosial, budaya, ekonomi dan politik sehingga mengakibatkan seseorang untuk memperoleh keinginan serta kebutuhan harus menawarkan, menciptakan serta bertukar sesuatu satu sama lainnya. Pemasaran dalam konteks pendidikan merupakan pengelolaan yang sistematis pertukaran yang diselenggarakan untuk mempromosikan misi-misi sekolah yang berlandaskan pemuasan baik bagi pemangku kebijakan ataupun masyarakat umumnya (Abrori, 2015).

Lebih lanjut pemasaran pendidikan merupakan kegiatan yang menitik beratkan pada kepuasan konsumen pendidikan itu sendiri. Kepuasan konsumen menurut Kotler dalam (Khasanah, 2015) dapat di ukur melalui beberapa cara, yaitu: a. Sistem keluhan serta saran (complaint and suggestion system); b) survey kepuasan konsumen (costumer satisfication surveys); c) pembeli bayangan (ghost shopping); d) analisis konsumen yang beralih (lost customer analysis). Lebih lanjut dimana konsumen dalam pendidikan adalah siswa dan masyarakat pada umumnya. Pemasaran pendidikan bertujuan memberikan akan kepuasan dalam pemenuhan kebutuhan dan keinginan dari konsumen pendidikan. Oleh sebab itu untuk mencapai tujuan pemasaran pendidikan tersebut, maka diperlukan suatu rencana yaitu strategi pemasaran yang tepat dan sesuai dengan keinginan dan kebutuhan konsumen pendidikan (Aulia, 2021).

Selain itu, fungsi pemasaran pendidikan adalah untuk menciptkan daya saing serta citra yang baik bagi para konsumen pendidikan sehingga menarik minat konsumen pendidikan dalam hal ini adalah siswa untuk memilih lembaga tersebut sebagai pelabuhan akan pemenuhan keinginan dan kebutuhan dalam pendidikan. Oleh karena itu sebelum lembaga pendidikan menerapkan strategi pemasaran yang tepat diperlukan usaha dalam mempelajari karakteristik sasaran (Fitriyanto et al., 2021). Hal ini dimaksudkan agar untuk melihat kesesuaian dalam penggunaan strategi pemasaran pendidikan dengan visi misi lembaga serta kebutuhan konsumen. Adapun unsur dalam strategi pemasaran pendidikan dapat diklasifikasikan kedalam tiga unsur utama, yaitu: 1) unsur strategi persaingan; 2) unsur taktik pemasaran; serta 3) unsur nilai pemasaran (Mundir, 2016).

Selain itu Fitriyanto et al., (2021) juga menambahkan jika dalam bidang pendidikan dibutuhkan dua konsep strategi pemasaran yang bisa dijadikan pertimbangan, yaitu: distinctive competence dan competitive 
4060 Strategi Pemasaran Jasa Pendidikan dalam Meningkatkan Daya Saing Sekolah Menengah Atas di Era New Normal - Moh. Rofiki, Lukman Sholeh, Abdur Rozak Akbar

DOI: https://doi.org/10.31004/edukatif.v3i6.1327

advantage. Dimana distinctive competence merupakan tindakan serta kegiatan yang dilakukan oleh lembaga pendidikan agar menjadi lebih baik dari pada kompetitor. Sedangkan competitive advantage merupakan tindakan serta kegiatan yang secara spesifik dikembangkan oleh lembaga pendidikan agar lebih unggul dengan perbedaan (differensiasi) lembaga tersebut dalam merebut pasar dengan para kompetitornya (Fradito et al., 2020).

Penggunaan istilah daya saing sebenarnya berakar dalam pemikiran darwinisme sosial, dimana teori ini berupaya memperluas data (ekstrapolation) konsep biologi seleksi alam dan bertahan yang paling cocok dalam sosiologi serta politik yang melahirkan ideologi kekuatan (Abduhzen, 2014). pengertian daya saing merupakan kekuatan untuk menjadi lebih baik serta unggul dari kompetitornya. Dengan redaksi yang berbeda dijelaskan bahwasanya daya saing ialah keterampilan untuk menunjukkan lebih baik, cepat serta bermakna dari pada pesaingnya dalam memperkuat posisi pasar, hubungan dengan lingkungan, meningkatkan dan mengembangkan kinerja secara terus menerus, serta menegakkan keadaan yang menguntungkan (Fachmi \& Setiawan, 2020). Selain itu daya saing juga merujuk pada potensi untuk mengungguli kompetitornya dalam satu bidang tertentu yang tidak dimiliki oleh pihak lain tersebut. Dengan melihat beberapa pengertian di atas dapat diberikan kesimpulan bahwasanya daya saing merupakan keterampilan yang digunakan untuk menjadi unggul dan cepat dalam satu bidang tertentu dari pada kompetitornya.

Dalam pengolahan manajemen pemasaran jasa pendidikan yang ditawarkan oleh lembaga pendidikan kepada masyarakat harus bisa meyakinkan masyarakat, sehingga yang terjadi minat masyarakat sebagai pengguna merasa tertarik dengan strategi yang ditawarkannya dan akhirnya masyarakat pun menyekolahkan anaknya ke lembaga pendidikan tersebut, pemasaran jasa pendidikan adalah menawarkan mutu layanan intektual secara menyeluruh dan komprehensip. Inti dari konsep pemasaran jasa pendidikan adalah memuaskan konsumenatau pengguna jasa pendidikan, dalam hal ini peserta didik sebagai pengguna utama.

Komponen-komponen pendidikan harus saling bekerjasama antara satu dengan yang lain komponenkomponen pendidikan tersebut seperti tujuan pendidikan, isi pendidikan, metode pendidikan, alat pendidikan, lingkingan pendidikan, pendidik, dan peserta didik (Sarifudin \& Maya, 2019). Pendidikan juga memerlukan strategi yang mantap dalam melaksanakan proses pendidikan dengan melihat situasi dan kondisi yang ada. Juga bagaimana agar dalam proses tersebut tidak ditemui hambatan serta gangguan baik internal maupun eksternal yang menyangkut kelembagaan atau lingkungan sekitarnya (Maya \& Lesmana, 2018).

Strategi dalam memasarkan produk lembaga pendidikan yang tepat adalahdengan menerapkanprinsip fokus bagaimana caranya agar masyarakat sebagai pengguna terpuaskan. Salah satu langka yang tepat adalah dengan memberikan kesan atau citra yang baik (positif) kepada masayarakat, maksud dari memberikan kesan (citra) adalah sebuah kesan positif yang diperoleholeh masyarakatsesuai dengan pengetahuan, pemahaman, dan pengalamanseseorang tentang sesuatu lembaga pendidikan. Citra tersebut terbentuk dari bagaimana sebuah lembaga pendidikan menjalankankegiatan operasionalpendidikan. Citra yang baik yang ditimbul oleh sebuah organisasi akan berdampak baik bagi lembaga pendidikan tersebut, sedangkan sebaliknya citra yang jelek akan berdampak merugikan terhadap organisasi tersebut (Tjiptono \& Diana, 2020). Dalam hal ini, pelanggan (peserta didik) jasa pendidikan terbagi dalam dua jenis, yaitu pelanggan internal dan pelanggan eksternal. Bertujuan dengan pelanggan internal ini adalah terdiri atas dewan guru, pustakawan, laboran, teknisi dan tenaga administrasi dan tenaga kependidikan lainnya. Sedangkan yang dimaksud dengan pelanggan eksternaladalah terdiri dari pelanggan primer (peserta didik), pelanggan skunder (orang tua, pemerintah,dan masyarakat), pelanggan tersier (pemakai atau penerima dari lulusan, baik dari lembaga pendidikan yang lebih tinggi maupun dari dunia usaha) (Mujamil Qomar, 2007:200). Kegiatan pemasaran jasa pendidikan sangatlah urgen karena keberadaan konsumen (pengguna) sebagai urat nadi manajemen bisnis lembaga pendidikan. Karena agar pengolahan manajemen pemasaran maka diperlukan adanya kebijakankebijakan yang dapat menyeimbangkan antara nilai mutu sekolah berbanding lurus dengan tuntutan dan harapan dari pengguna dalam hal ini adalah masyarakat. Seperti adanya suatu pengolahan terhadap kinerja 
4061 Strategi Pemasaran Jasa Pendidikan dalam Meningkatkan Daya Saing Sekolah Menengah Atas di Era New Normal-Moh. Rofiki, Lukman Sholeh, Abdur Rozak Akbar

DOI: https://doi.org/10.31004/edukatif.v3i6.1327

guru, yaitu berupa kegiatan supervisi. Malalui pengawasan, sosialisasi, dan pelatihan guru diharapkan memiliki kompetensi sebagai pedoman dalam mengajar serta telah memiliki keterampilan-keterampilan dalam mengajar dan mendidik (Sarifudin, 2019: 51).

Dalam dunia pendidikan, daya saing merupakan sebuah keniscayaan yang harus dilakukan oleh lembaga pendidikan agar dapat survive dan kompetitif serta meningkatkan kapabilitas lembaga pendidikan tersebut. Menurut Porter (2008, p. 419) terdapat indikator yang dapat menentukan daya saing lembaga pendidikan, yaitu: a) harga yang bersaing; b) kualitas dari produk yang ditawarkan, serta c) keunggulan dari produk yang ditawarkan. Lebih lanjut dimana dalam era sekarang ini banyak terjadi kesenjangan kapabilitas lembaga pendidikan dikarenakan dipengaruhi oleh beberapa faktor yang tentunya juga akan berpengaruh dalam keberlangsungan lembaga pendidikan itu sendiri. Terkait hal ini dapat digambarkan sebagai berikut.

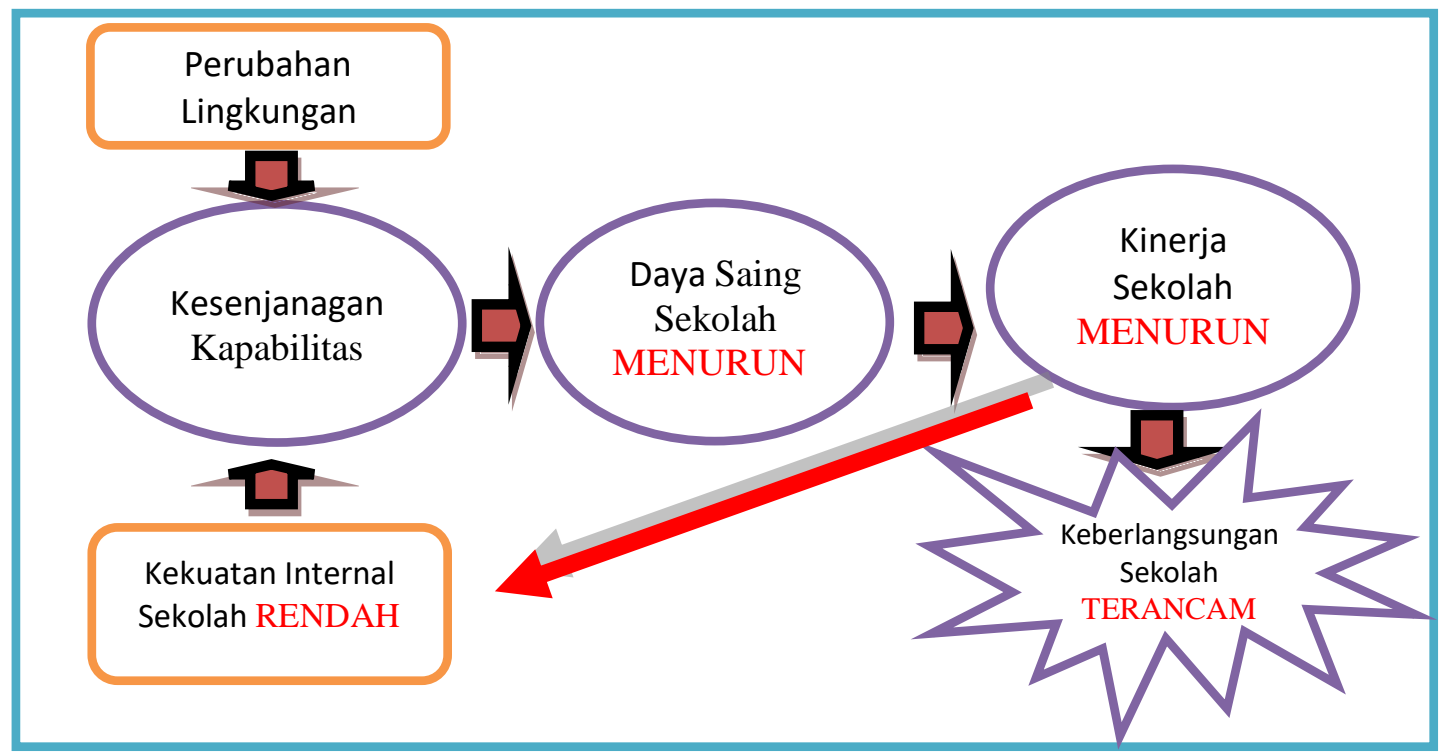

Gambar 1. Permasalahan Kesenjangan Kapabilitas Sekolah (Rahayu, 2010)

Dalam menyikapi fenomena tersebut sangat dibutuhkan keunggulan besaing. Hal ini tentunya dilihat dari peran keunggulan bersaing sangat penting dalam kinerja lembaga pendidikan sehingga nantinya lembaga pendidikan mempunyai kemampuan dan keunggulan yang kompetitif yang juga akan menentukan strategi pemasaran yang efektif. Lebih lanjut keunggulan bersaing diciptakan oleh lembaga pendidikan dengan peran serta pemangku kebijakan yaitu kepala sekolah yang mempunyai otoritas dalam menentukan arah kebijakan lembaga yang dikelolanya. Berdasarkan pembahasan di atas, maka penulis sangat tertarik untuk mengkaji suatu penelitian tentang strategi pemasaran jasa pendidikan dalam meningkatkan daya saing sekolah menengah atas di era new normal.

\section{METODE PENELITIAN}

Penelitian ini menggunakan penelitian kualitatif yang dijabarkan secara deskriptif dengan pendekatan studi kasus (Nugrahani \& Hum, 2014). Penelitian ini diharapkan dapat mendeskipsikan secara utuh dan menyeluruh berkaitan dengan strategi pemasaran jasa pendidikan dalam meningkatkan daya saing sekolah di SMA Nurul Jadid Paiton Probolinggo.

Teknik pengumpulan data yang digunakan dalam penelitian ini adalah observasi, interview, serta studi dokumentasi. Dimana observasi digunakan untuk mengetahui langkah-langkah yang dilakukan berkaitan dengan daya saing sekolah. Interview digunakan untuk mendapat data secara langsung dengan informan penelitian yaitu kepala sekolah, bagian humas, guru, serta siswa. Dokumentasi digunakan untuk mendapatkan data yang berkaitan dengan fokus penelitian. 
4062 Strategi Pemasaran Jasa Pendidikan dalam Meningkatkan Daya Saing Sekolah Menengah Atas di Era New Normal - Moh. Rofiki, Lukman Sholeh, Abdur Rozak Akbar

DOI: https://doi.org/10.31004/edukatif.v3i6.1327

Penelitian ini dalam analisis datanya menggunakan teknik analisis data kualitatif. Dimana dalam pandangan Miles dan Hubberman analisis kualitatif terdiri dari mereduksi data, menyajikan data, seta penarikan kesimpulan (Arikunto, 2010)

\section{HASIL DAN PEMBAHASAN PENELITIAN}

Strategi pemasaran jasa pendidikan yang dilaksanakan di lembaga pendidikan SMA Nurul Jadid dapat dijabarkan sesuai dengan strategi bauran jasa pendidikan yaitu:

\section{Strategi Produk}

Produk yang ditawarkan oleh SMA Nurul Jadid merupakan produk yang terealisasikan di visi sekolah yaitu mencetak generasi bangsa berakhlaqul karimah, berprestasi, berwawasan lingkungan dan berdaya saing global. Dimana visi tersebut diimplementasikan dalam beberapa program sekolah yaitu kegiatan pembelajaran yang terintegrasi dengan pesantren, sekolah unggul serta sekolah penggerak.

Kegiatan pembelajaran yang terintegrasi dengan pesantren merupakan pembelajaran pesantren yang diwajibkan dalam pembelajaran sekolah misalnya pembelajaran furudhul 'ainiyah dimana pembelajaran ini merupakan syarat kenaikan dan kelulusan peserta didik, selain itu juga mensinkronkan pendidikan diniyah dengan pendidikan yang ada disekolah. Sekolah unggul merupakan sekolah yang unggul dari segi pelayanan, unggul dari segi prestasi serta unggul dari segi penampilan. Sekolah penggerak merupakan sekolah yang terdiri dari eksternal dan internal. Dimana yang eksternal ialah program sekolah yang bisa didesiminasikan kepada sekolah lain atau sekolah mitra contohnya 1) pengelolaan pembelajaran bahasa mandirin yang sudah dimulai sejak kurikulum KBK dimana guru bahasa mandarin didatangkan langsung dari china dan sekolah juga mempunyai HSK semacam Toefl khusus pembelajaran mandarin; 2) pengelolaan media internal sekolah mulai dari wesite sekolah, instagram sekolah, facebook sekolah sebagai media representasi sekolah; 3) pengelolaan sekolah berupa majalah sekolah MISI. Sedangkan yang internal ialah program yang diajarkan di dalam yang meliputi mewujudkan jiwa-jiwa enterprenuer serta mewujudkan sekolah herbal.

Lebih lanjut sekolah menerapkan sistem SKS layaknya perguruan tinggi dimana siswa dapat memilih mata pelajaran yang akan ditempuh sehingga memungkinkan peserta didik lulus dalam dua tahun atau tiga tahun atau bahkan empat tahun. Akan tetapi yang paling menentukan hal tersebut adalah ketuntasan dalam pembelajaran furudhul 'ainiyahnya. Semua program sekolah merupakan sebuah lompatan besar yang diberikan sekolah kepada pelanggan jasa pendidikan sehingga pelanggan sekolah dapat mendapatkan produk yang ditawarkan oleh sekolah secara maksimal. Berdasarkan jasa pendidikan sekolah memiliki tugas untuk mengantarkan siswanya baik dari segi akademik dan non akademik dapat mengantarkan siswanya kejenjang berikutnya.

\section{Strategi Harga}

Harga yang harus dibayarkan oleh wali santri SMA Nurul Jadid dalam per triwulan adalah Rp. 1.980.000, dengan rincian untuk pembayaran SPP, buku paket dan kitab diniyah. Wali murid difasilitasi dengan kemudahan bertransaksi melalui bank mitra yang telah ditunjuk oleh pihak pesantren dan sekolah dalam melakukan pembayaran. Selain itu di dalam pembayarannya juga sudah menggunakan virtual account sehingga sangat memudahkan dan meminalisir terjadinya salah transfer dll.

\section{Strategi Tempat}

Lokasi sekolah SMA Nurul Jadid berada dalam lingkungan Pondok Pesantren Nurul Jadid tepatnya Jl. KH. Zaini Mun'im Karanganyar Paiton Probolinggo yang berada tidak jauh dari jantung kota probolinggo dan tidak jauh dari PLTU Paiton yang menjadi pemasok listrik untuk Jawa dan Bali. Lokasi dapat diakses melalui kendaraan umum karena berada kurang lebih $3 \mathrm{Km}$ dari jalan provinsi. 
4063 Strategi Pemasaran Jasa Pendidikan dalam Meningkatkan Daya Saing Sekolah Menengah Atas di Era New Normal - Moh. Rofiki, Lukman Sholeh, Abdur Rozak Akbar

DOI: https://doi.org/10.31004/edukatif.v3i6.1327

\section{Strategi Promosi}

Terdapat banyak strategi promosi yang dilakukan oleh SMA Nurul Jadid diantaranya adalah menggunakan media eletronik misalnya webset sekolah yaitu www.smanj.sch.id, melalui facebook sekolah, melalui ikatan alumni yang tersebar didaerah tapal kuda dan daerah besar semisal Surabaya, Malang, Jakarta,dll. Selain itu promosi yang dilakukan dengan mengadakan event atau kegiatan baik tingkat nasional ataupun internasional seperti pidato bahasa mandarin, bahasa arab dll. Lebih lanjut selain mengadakan event, SMA Nurul Jadid juga sering mendelegasikan siswanya dalam event nasional ataupun internasional dan tidak jarang mendapatkan juara dalam event tersebut seperti juara dua pada ajang bahasa mandarin chinese bridge nasional dan masih banyak lagi.

\section{Strategi Orang}

Strategi sumberdaya mempunyai peran yang sangat vital dalam keberlangsungan proses belajar dalam mencapai tujuan pendidikan. Oleh sebab itu penting dilaksanakan suatu kegiatan yang dapat meningkatkan sumberdaya manusia yang berkualitas. Dalam mencapai hal tersebut SMA Nurul Jadid sering mengadakan Focus Group Discussion (FGD), pelatihan-pelatihan dan pendelegasian guru untuk melanjutkan studi baik dalam lingkungan kampus pondok atau kampus diluar pondok misalnya UM, Unisma, Unesa dll. sSelain itu juga sering mendatangkan pakar pendidikan untuk menjadi guru tamu, mengadakan workshop serta seminar pendidikan dan kewirausahaan. Selain itu dalam pengrekrutan tenaga pendidikan dilakukan melalui mekanisme yang berlaku dalam pondok pesantren dengan beberapa ujian seperti baca al-Qur'an, microteaching, dll.

\section{Strategi Bukti Fisik}

Bukti fisik yang ditampilkan oleh SMA Nurul Jadid adalah bangunan permanen lantai dua dan tiga yang digunakan untuk melakukan pembelajaran di sekolah. Terdapatnya fasilitas-fasilitas penunjang peserta didik dalam melakukan kegiatan sekolah seperti laboratorium (Fisika, Kimia,Biologi), laboratorium komputer, laboratorium bahasa, laboratorium agama, laboratorium IPS, serta laboratorium live skill. Selain itu terdapat juga bangunan green house dan lab budidaya jamur tiram yang digunakan siswa untuk melaksanakan kewirausahaan atau enterprenuership sehingga mendorong siswa untuk membangkitkan jiwa-jiwa pengusaha. Siswa dalam melakukan praktek penyiaran juga disediakan media yang berupa radio SMANJ sehingga melatih siswa dalam menyampaikan berita melaui siaran udara yang dilakukan di sekolah.

\section{Strategi Proses}

Dari aspek proses SMA Nurul Jadid secara umum mengikuti regulasi yang ditetapkan oleh Kementrian Pendidikan Nasional dan regulasi yang ditentukan oleh pondok pesantren. Regulasi yang diknas misalnya struktur kurikulum dan alokasi waktu berbagai mata pelajaran. Sedangkan yang dari pesantren adalah program diniyah yang dilaksanakan pada hari sabtu dan minggu sedangkan senin sampai kamis pelajaran umum. Secara subtansial tidak melanggar regulasi pemerintah, secara pelaksanaan diniyah mengawal program pesantren dan sekolah sehingga program yang ditentukan diperoleh dan program pesantren juga diperoleh dengan baik. Dengan demikian SMA Nurul Jadid melaksanakan dua program sekaligus dalam satu semester sehingga pendidikan umum dan pendidikan diniyah dapat diperoleh oleh peserta didik melalui pembelajaran di sekolah.

Berdasarkan paparan hasil penelitian di atas, secara umum strategi yang digunakan oleh SMA Nurul Jadid dalam pemasaran jasa pendidikan untuk meningkatkan daya saing sekolah merupakan strategi menggunakan bauran pemasaran secara umum. Dimana bauran pemasaran jasa pendidikan tersebut terdiri dari product, price, place, promotion, people, physical evidence, serta process. Akan tetapi dalam melaksanakan pemasaran jasa pendidikan tersebut SMA Nurul Jadid mengintegrasikan apa yang menjadi program pesantren dalam proses pembelajaran yang dilaksanakan. Hal ini diperkuat hasil wawancara dengan kepala sekolah dimana sekolah mempunyai program tahunan yaitu mengintegrasikan sekolah dengan pesantren, sekolah 
4064 Strategi Pemasaran Jasa Pendidikan dalam Meningkatkan Daya Saing Sekolah Menengah Atas di Era New Normal - Moh. Rofiki, Lukman Sholeh, Abdur Rozak Akbar

DOI: https://doi.org/10.31004/edukatif.v3i6.1327

unggul serta sekolah penggerak. Dari bauran jasa pendidikan yang dilaksanakan di SMA Nurul Jadid bahwasanya strategi pemasaran tersebut dapat disederhanakan menjadi tiga strategi pemasaran yaitu: strategi pemasaran secara langsung, strategi pemasaran tidak langsung, serta strategi pemasaran diferensiasi.

Strategi pemasaran jasa pendidikan secara langsung merupakan strategi yang dilakukan dengan pemanfaatan beberapa media baik itu elektronik, cetak atau media secara lisan (word of mouth) seperti website sekolah, majalah sekolah, serta melaui ikatan alumni. Strategi pemasaran jasa pendidikan tidak langsung merupakan strategi yang dilakukan dengan mengadakan atau ikut serta dalam sebuah acara atau event melalui aplikasi zoom, google meet baik skala regional, nasional, serta internasional. Dan strategi pemasaran jasa pendidikan deferensiasi merupakan strategi pemasaran yang dilakukan dengan menonjolkan perbedaan dan keunggulan dengan sekolah lain dalam hal ini adalah program diniyah, furudhul 'ainiyah, program bahasa mandarin yang sudah mempunyai HSK atau toefl dalam bahasa inggris, serta program penerapan SKS layaknya perguruan tinggi yang memungkinkan peserta didik dapat menyelesaikan sekolah hanya dalam waktu relatif singkat yaitu dua tahun. Hal ini dikarenakan SMA Nurul Jadid merupakan sekolah percontohan untuk bahasa mandarin tingkat Jawa Timur. Oleh sebab itu menjadi keunggulan tersendiri bagi sekolah yang berada dalam lingkungan pondok pesantren tersebut.

\section{KESIMPULAN}

Berdasarkan hasil dan pembahasan di atas, bahwasanya pendidikan sebagai bagian yang terintegrasi dalam kehidupan manusia perlu dikelola dengan profesional guna dapat memenangkan daya saing demi tetap survive dalam era globalisasi. Agar tujuan tersebut dapat tercapai secara maksimal lembaga pendidikan perlu melakukan suatu aktivitas atau kegiatan yaitu dengan melakukan strategi pemasaran jasa pendidikan. Keunggulan bersaing tentunya lembaga pendidikan akan mempunyai kemampuan yang kompetitif serta dapat memilih strategi pemasaran yang efektif. Implementasi strategi pemasaran jasa pendidikan dalam meningkatkan daya saing sekolah dapat dilakukan melaui bauran jasa pendidikan yang terdiri dari beberapa komponen yaitu: product, price, place, promotion, people, physical evidence, serta process. Dimana strategi tersebut dapat kemudian dikelompokkan atau disederhanakan menjadi tiga strategi pemasaran jasa pendidikan, yaitu strategi pemasaran jasa pendidikan secara langsung, strategi pemasaran jasa pendidikan secara tidak langsung, serta strategi pemasaran jasa pendidikan deferensiasi.

\section{DAFTAR PUSTAKA}

Abduhzen, M. (2014). Pendidikan Untuk Daya Saing.

Abrori, M. (2015). Strategi Pemasaran Lembaga Pendidikan untuk Meningkatkan Jumlah Peserta Didik di PG/TK Samarinda. SYAMIL: Jurnal Pendidikan Agama Islam (Journal of Islamic Education), 3(2), 227-245. https://doi.org/10.21093/sy.v3i2.245

Ananda, R., \& Fadhilaturrahmi, F. (n.d.). Analisis Kemampuan Guru Sekolah Dasar dalam Implementasi Pembelajaran Tematik di SD. Jurnal Basicedu, 2(2), 11-21.

Arikunto, S. (2010). Metode peneltian. Jakarta: Rineka Cipta.

Ariwibowo, M. E. (2019). Strategi Pemasaran Lembaga Pendidikan Tinggi Swasta. SCIENTIFIC JOURNAL OF REFLECTION: Economic, Accounting, Management and Business, 2(2), 181-190. https://doi.org/10.5281/zenodo.2628082

Aulia, R. I. (2021). Pengaruh Manajemen Strategi Pendidikan Dalam Meningkatkan Mutu Dan Daya Saing. EDUKATIF: JURNAL ILMU PENDIDIKAN, 3(4), 1578-1586.

Diana, E., \& Rofiki, M. (2020). Analisis Metode Pembelajaran Efektif Di Era New Normal. Jurnal Review Pendidikan Dan Pengajaran, 3(2), 336-342.

Fachmi, M., \& Setiawan, I. P. (2020). Strategi Meningkatkan Kepuasan Nasabah Analisis Kasus melalui Riset 
4065 Strategi Pemasaran Jasa Pendidikan dalam Meningkatkan Daya Saing Sekolah Menengah Atas di Era New Normal - Moh. Rofiki, Lukman Sholeh, Abdur Rozak Akbar

DOI: https://doi.org/10.31004/edukatif.v3i6.1327

di Industri Asuransi Jiwa. CV. Pustaka Learning Center.

Faizin, I. (2017). Strategi pemasaran jasa pendidikan dalam meningkatkan nilai jual madrasah. Madaniyah, $7(2), 261-283$.

Fitriyanto, F., Shinta, M. R., La Ode, Y., \& Mutiah, T. (2021). Implementasi Manajemen Pemasaran Jasa di SMK Taruna Bhakti Depok. Jurnal Mitra Manajemen, 5(5), 312-324.

Fradito, A., Suti'ah, \& Muliyadi. (2020). Strategi Pemasaran Pendidikan Dalam Meningkatkan Citra Sekolah. Al-Idarah: Jurnal Kependidikan Islam, 10(1), 12-22.

Kemendikbud RI. (2016). KBBI Daring.

Khasanah, A. (2015). Pemasaran Jasa Pendidikan Sebagai Strategi Peningkatan Mutu Di Sd Alam Baturraden. El-Tarbawi, 8(2), 161-176. https://doi.org/10.20885/tarbawi.vol8.iss2.art4

Labaso, S. (2019). Penerapan Marketing Mix sebagai Strategi Pemasaran Jasa Pendidikan di MAN 1 Yogyakarta. MANAGERIA: Jurnal Manajemen Pendidikan Islam, 3(2), 289-311. https://doi.org/10.14421/manageria.2018.32-05

Laurence, R. J., \& Glucek, W. F. (1998). Manajemen Strategis dan Kebijakan Perusahaan (Ketiga). Erlangga.

Margareta, R. T. E., Ismanto, B., \& Sulasmono, B. S. (2018). Strategi Pemasaran Sekolah Dalam Peningkatan Minat Peserta Didik Berdasarkan Delta Model. Kelola: Jurnal Manajemen Pendidikan, 5(1), 1-14. https://doi.org/10.24246/j.jk.2018.v5.i1.p1-14

Maya, R., \& Lesmana, I. (2018). Pemikiran Prof. Dr. Mujamil Qomar, M. Ag. tentang Manajemen Pendidikan Islam. Islamic Management: Jurnal Manajemen Pendidikan Islam, 1(02), 291-316.

Mundir, A. (2016). Strategi Pemasaran Jasa Pendidikan Madrasah. Malia, 7(1), 27-40.

Nugrahani, F., \& Hum, M. (2014). Metode penelitian kualitatif. Solo: Cakra Books.

Porter, M. E. (2008). Competitive Advantage: Menciptakan dan Mempertahankan Kinerja Unggulan. Kharisma Publishing Group.

Rahayu, A. (2010). Analisis Sumber Daya Sekolah dan Program Penciptaan Nilai dalam Meningkatkan Daya Saing Sekolah. Educationist, IV(1), 48-56.

Sarifudin, S., \& Maya, R. (2019). Implementasi Manajemen Pemasaran Jasa Pendidikan dalam Meningkatkan Kepuasan Pelanggan di Madrasah Aliyah Terpadu (MAT) Darul Fallah Bogor. Islamic Management: Jurnal Manajemen Pendidikan Islam, 2(02), 133-151.

Siahaan, K. W. A., Lumbangaol, S. T. P., Marbun, J., Nainggolan, A. D., Ritonga, J. M., \& Barus, D. P. (2021). Pengaruh Model Pembelajaran Inkuiri Terbimbing dengan Multi Representasi terhadap Keterampilan Proses Sains dan Penguasaan Konsep IPA. Jurnal Basicedu, 5(1), 195-205.

Tjiptono, F., \& Diana, A. (2020). Pemasaran. 